\title{
Assessing the Effectiveness of Innovation Management in the Hospitality Industry: A Study of Selected Hotels in South-East, Nigeria
}

\author{
Magnus M. Ofondu \\ Lecturer, Department of Management, Abia State University, P.M.B. 2000, Uturu Abia \\ State, Nigeria \\ E-mail: Magmof2012@yahoo.com
}

Received: March 22, 2018 Accepted: April 3, 2018 Published: June 21, 2018

doi:10.5296/bms.v9i1.13300ＵRL: https://doi.org/10.5296/bms.v9i1.13300

\begin{abstract}
This study focused on assessing the effectiveness of innovation management in the hospitality industry. The inability of the change managers of these hotels to meet their expected organizational goals even as they strive to inject something new to meet the ever-rising demand of their clients made this study so essential. To achieve this objective, both primary and secondary data were employed. From a given population of 966, a sample size of 283 was derived using the Taro Yamane’s formula. A survey research design was also employed, and the study proved to be valid and reliable given a content validity and a Cronbach alpha of 0.863 . The techniques adopted in analyzing the data were both the descriptive and inferential statistics. Spearman Rank Correlation Coefficient was used in testing the hypotheses. The result of the findings reveals that there is a significant association between the extent of innovation at a given period and the performance of the firms; innovation management does significantly correlate to the growth of the firms. Based on these findings, the researcher concluded that innovation management in the hospitality industry is effective. The researcher therefore recommends among others that there should be a concrete organizational arrangement to improve on the practice of innovation as often as possible in order to enhance the performance of the organizations and be effective.
\end{abstract}

Keywords: Effectiveness, Innovation management, Hospitality Industry 


\section{Introduction}

Change, innovation, quality, expertise and creativity are familiar concepts when it comes to innovation management. During the past decades, numerous theories and concepts have been developed to face the challenges of complex societies and to fundamentally improve organizational structures. Around the 1930s Schumpeter started studying how the capitalist system was affected by market innovations. After analyzing the capitalist model, Schumpeter tried to understand what companies would be in a better position to innovate. He developed a theory where a company's ability to innovate was mainly connected to its size. Initially he defended that small companies should be in a better position due to their flexibility while large companies might get trapped in bureaucratic structures. Some years later, however, he changed his view, stating that larger corporations with some degree of monopolistic power could have an advantage to develop innovations. Compared to smaller firms such large corporations have better resources and more market power. Unfortunately the innovation theory was only a marginal part of Schumpeter's work; it was derived from his analysis of the different economic and social systems. The theory therefore has no empirical foundation at all; there is no strong evidence to support a relationship between the size of a company and its ability

to innovate. (http://innovationzen.com/blog/2006/07/29/innovation-management-theory-part-1/)

In consonance with this is a likewise innovation model as developed by Schumpeter (1934). He is of the view that continuous innovation activity is the key source of long-term firm success (Rosenbusch, Brinckmann, and Bausch, 2011). This simply implies that a strong crusade and application of innovation management will definitely help firms to achieve effectiveness. It has therefore become the continuous claim of contemporary scholars that firms which fail to engage in innovation are putting themselves at great risk (Kotler, 2003). In another view, it has been noted that due to the heightened level of competition and shortened product life cycle, firm's ability to generate innovations may be more important than ever in allowing firms to improve performance and maintain competitive advantage (Artz, Norman, Hatfield, and Cardinal, 2010). Based on this argument, in today's intense and sophisticated competitive environment it is not surprising to see that innovation has become a requisite objective for all firms (Lippit, 2006). Therefore it is generally expected that all firms should innovate regardless of their size or sector in order to compete and survive in the market (Elci and Karatyh, 2009).

Innovation management is based on some of the ideas put forth by Schumpeter during the 1930s, who identified innovation as a significant factor in economic growth (Scocco, 2006). His book "Capitalism, Socialism and Democracy" first fully developed the concept of creative destruction. Creativity is the basis of innovation management; the end goal is a change in services or business process. Innovative ideas are the result of two consecutive steps, imitation and invention (Godin, 2008).

The goal of innovation management within a company is to cultivate a suitable environment to encourage innovation (Rickne, Laestadius, and Etzkowitz, 2012). 
Environmental trends such as globalization of markets, technological revolution, government policy somersault and deregulation are rapidly changing the competitive structure of markets in such a way that the competitive advantage of organizations is often attenuated (Andreu, Baiget and Canals, 2003; Oghojafor, Olamitunji, and Sulaiman, 2011). Consequently, organizations are under great pressure so much so that the turbulent environmental condition is constantly impinging on their capacity to be innovative in the eyes of their demanding customers (Andreu, Baiget and Canals, 2003; Karami, 2008; Duygulu and Ozeren, 2009).

\subsection{Statement of the Problem}

During the course of the last decades, all industries, from manufacturing to service, have felt the need to gradually introduce new organizational concepts, exposing themselves to a plethora of changes in order to meet the growing challenges posed by markets and new competitors. Innovation management has come to be seen as one of the key antidotes to the plenitude of problems confronting today's organizations as a result of environmental dynamism.

At present, how to introduce change for effectiveness through innovation management is one of the major challenges confronting not only organizations but also individuals who, on the one hand, have to stay in stride with organizations as they undergo their process of change or, on the other hand, are in charge of enabling change by implementing and coordinating processes of change and innovation within the organizational structures. There is the tendency to agree that the approaches of some of these managers are unsystematic, therefore are not likely to offer the expected result. The central problem that necessitates this research is the fact that even as the change managers/agents of these hotels are tirelessly working to inject something 'new' into their organizations in order to meet the ever-rising demand of their clients, they still have not met their expected organizational goals. This owes largely to the ever-witnessed short fall in the performance of the organizations and a slim and lopsided growth rate.

Given this whole gamut of problems confronting these hotels which hinder them from achieving their goals, managing innovation becomes increasingly difficult and expensive especially as it affects the hospitality industry which may not quantify their reward over their commitment. In reaction to these, the researcher has therefore resolved to make a concrete attempt to solve the problems as stated in this study.

\subsection{Objectives of the Study}

The broad objective of this study is to assess the effectiveness of innovation management in the hospitality industry. The specific objectives are:

1) To ascertain whether there is any significant association between the extent of innovation at any given period and the performance of the firms.

2) To identify if innovation management significantly correlates to the growth of the firms. 


\subsection{Statement of the Hypotheses}

$\mathrm{HO}_{1}$ : There is no significant association between the extent of innovation at any given period and the performance of the firms.

$\mathrm{HO}_{2}$ : Innovation management does not significantly correlate to the growth of the firms.

\section{Literature Review}

\subsection{Conceptual Framework}

The spirit of innovation is essential for keeping an organization vital and in maintaining a competitive advantage. Innovation is the activity of creating new ideas and converting them into useful applications- specifically new goods and services. Better still, it is the process of taking a creative idea and turning it into a useful product, service or method of operation. In his opinion, Nelson (1968 as cited in Okpara, 2013) defines innovation as the process by which new products and techniques are introduced into the economic system. Innovation is the adoption of new approaches by an organization (Lee and Yu, 2010). Given all these, innovation management is the management of innovation process. It refers to both product and organizational innovation.

Innovation management describes the decisions, activities and practices that move an idea to realization for the purpose of generating business value. It is managing the investment in creating new opportunities for generating customer value that are needed to sustain and grow the business or company (http//:www.innovation-management.org).

According to Schilling (2013), innovation management is about how organizations and their employees manage their innovation activities.

In the opinion of Rouse (2016), innovation management involves the process of managing an organisation's innovation procedure, starting at the initial stage of ideation, to its final stage of successful implementation. It encompasses the decisions

\subsection{Types of Innovation in Service Firms}

Several articles suggest and use typologies of what is included in the concept of "innovation" in the service firms. Some of these typologies specify in what part of the service firm innovation takes place. Hipp, Thether and Miles (2000), make a distinction between three types of innovations:

1) Service innovations, which include innovation in the service offer per se in the form of introductions of new or significantly improved services;

2) Process innovations, which include new and improved work methods in the process by which a specific service is produced; and

3) Organisational innovations, which is not limited to the individual service production process but includes significant improvements in wider organizational structures or 
processes.

\subsection{Theoretical Framework}

This paper adopts the Diffusion of Innovation Theory as given by Everett Rogers in 1962. Diffusion of innovation is a theory that seeks to explain how, why, and at what rate new ideas and technology spread through cultures. It originated in communication to explain how, over time, an idea or product gains momentum and diffuses (or spreads) through a specific population or social system. The end result of this diffusion is that people, as part of a social system, adopt a new idea, behavior, or product (LaMorte, 2016). Everett Rogers, a professor of communication studies, popularized the theory in his book Diffusion of Innovation; the book was first published in 1962, and is now in its fifth edition (Rogers, 2003).Rogers argues that diffusion is the process by which an innovation is communicated through certain channels over time among the participants in a social system. His methodologies are closely followed in recent diffusion research, even as the field has expanded into, and been influenced by other methodological disciplines such as social network analysis and communication (Easley and Klemberg, 2010).

Rogers proposes that four main elements influence the spread of a new idea: the innovation itself, communication channels, time, and a social system. According to LaMorte (2016), researchers have found that people who adopt an innovation early have different characteristics than people who adopt an innovation later. When promoting an innovation to a target population, it is important to understand the characteristics of the target population that will help or hinder adoption of the innovation. There are five established adopter categories, and while the majority of the general population tends to fall in the middle categories, it is still necessary to understand the characteristics of the target population. When promoting an innovation, there are different strategies used to appeal to the different adopter categories.

1) Innovators - These are people who want to be the first to try the innovation. They are venturesome and interested in new ideas. These people are very willing to take risks, and are often the first to develop new ideas. Very little, if anything, needs to be done to appeal to this population.

2) Early Adopters - These are people who represent opinion leaders. They enjoy leadership roles, and embrace change opportunities. They are already aware of the need to change and so are very comfortable adopting new ideas. Strategies to appeal to this population include how-to manuals and information sheets on implementation. They do not need information to convince them to change.

3) Early Majority - These people are rarely leaders, but they do adopt new ideas before the average person. That said, they typically need to see evidence that the innovation works before they are willing to adopt it. Strategies to appeal to this population include success stories and evidence of the innovation's effectiveness.

4) Late Majority - These people are skeptical of change, and will only adopt an innovation 
after it has been tried by the majority. Strategies to appeal to this population include information on how many other people have tried the innovation and have adopted it successfully.

5) Laggards - These people are bound by tradition and very conservative. They are very skeptical of change and are the hardest group to bring on board. Strategies to appeal to this population include statistics, fear appeals, and pressure from people in the other adopter groups.

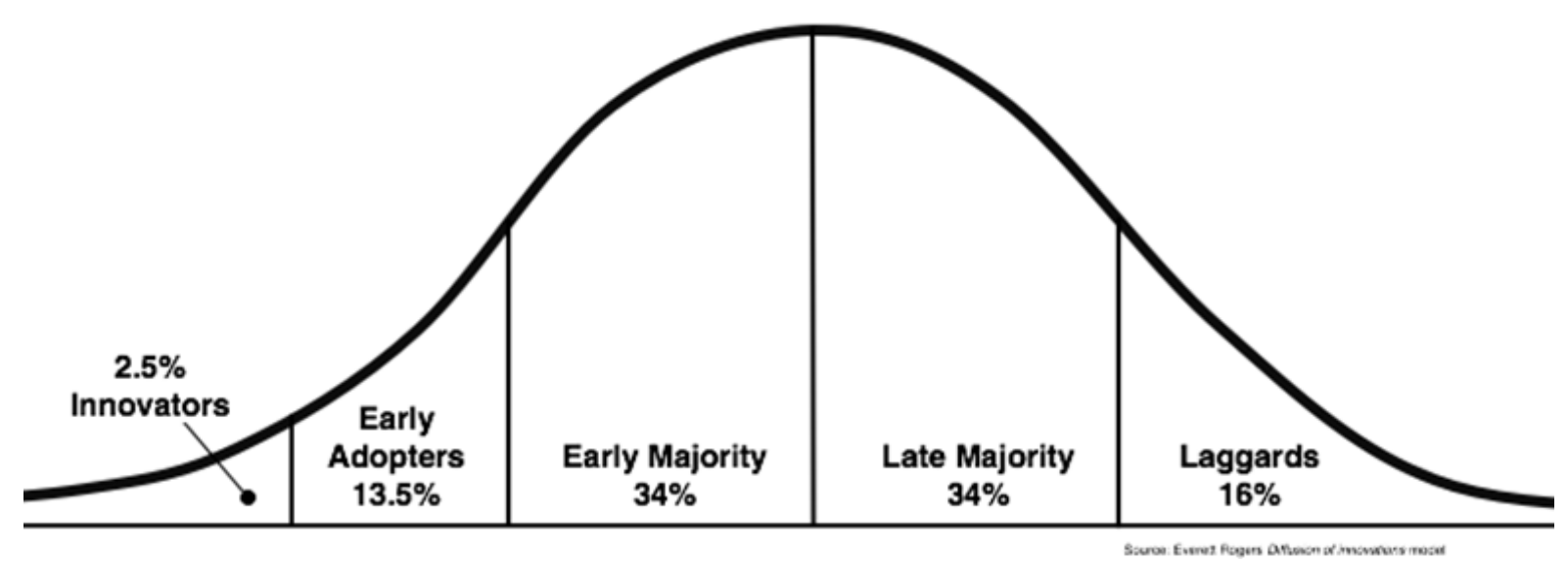

Fig. 1. Everett Rogers’ Diffusion of Innovation Theory.

Source: http://blog.leanmonitor.com/early-adopters-allies-launching-product/

\subsection{Empirical Framework}

A few empirical studies have been reviewed relating to the effectiveness of innovation management in the hospitality industry.

Calantone, Cavusgil, and Zhao, (2002) developed a framework for studying the relationship between learning orientation, firm innovativeness and firm performance in the U.S manufacturing and service industries. The study in its methodology followed an in-depth interview method and the data were analyzed using the path analysis method. Their study revealed that firm innovativeness is positively related to firm performance. This entails that a well-tailored innovation management brings about effectiveness in the organization.

Cho and Pucik, (2005) examined the relationship between innovativeness, quality, growth, profitability, and market value at the firm level in the U.S finance industry by using structural equation modeling method. Their study indicated that innovativeness mediates the relationship between quality and growth, quality mediates the relationship between innovativeness and profitability.

Therrien, Doloreux, and Chamberlin, (2011) investigated on the relationship between innovation and firm performance: an empirical evidence from Turkish Automotive Supplier Industry. The survey of this study was conducted on top level managers of 113 firms operating in the automotive supplier industry which is one of the most innovative industries in Turkey, as 
of the year 2011. The obtained data from the questionnaires were analyzed using regression method and through the SPSS statistical package program. Analysis results demonstrated that technological innovation (product and process innovation) has significant and positive impact on firm performance, but no evidence was found for a significant and positive relationship between non-technological innovation (organizational and marketing innovation) and firm performance.

A recent research by Hajar, (2015) on the effect of business strategy on innovation and firm performance in small industrial sector examined the relationship between innovation and performance of wooden furniture manufacturing SMEs in Indonesia. The study reveals that innovation has a positive effect on firm's performance. Notwithstanding, a study on innovation and SMEs performance find that innovation culture and strategy are key drivers of performance (Terziovski, 2010 ).

\section{Methodology}

The research deign for this study was the descriptive/survey method. Data were collected using both the primary and secondary sources. The population of the study was 966 members of staff of the selected firms, and the sample size determined using Taro Yamane's (1964) formula as cited in Alugbuo, Umeaka and Eriama (2012) was 283 and which were also used for analysis. In selecting the respondents, the simple random sampling technique was adopted. The research instrument was said to be reliable given a Cronbach alpha result of 0.863 (see appendix). The statistical technique employed in collecting the data was Semantic Differential technique. It consists of pairs of bipolar adjectives or phrases with cues spaced in between (Okpara, 1998:4). The rating has a degree ranging from positive to negative. The rating model containing seven points can be shown as follows: +3 (Strongly agree); +2 (Agree); +1 (Slightly agree); 0 (Neutral); -1 (Slightly disagree); -2 (Disagree); -3 (Strongly disagree). In analyzing the data, the descriptive statistics were employed, while the Spearman Rank Correlation Coefficient was used in testing the hypotheses. The analysis was done with the help of the Statistical Package for Social Sciences (SPSS) version 19.

\section{Data Presentation and Analysis}

This section provides results of analyzed data. This is to add value and meaning to the raw data generated, make it easy for users to summarize the information presented, aid the researchers to draw conclusion from the generated data and to provide meaningful base to critical research decisions (Agu, 2016).

Table 1. Demographic Distribution of the Respondents

\begin{tabular}{|l|l|l|l|}
\hline S/N & Demographic Characteristics & Frequency & Percentage \\
\hline 1 & Gender: Male & 184 & 65 \\
& & 99 & 35 \\
\hline
\end{tabular}




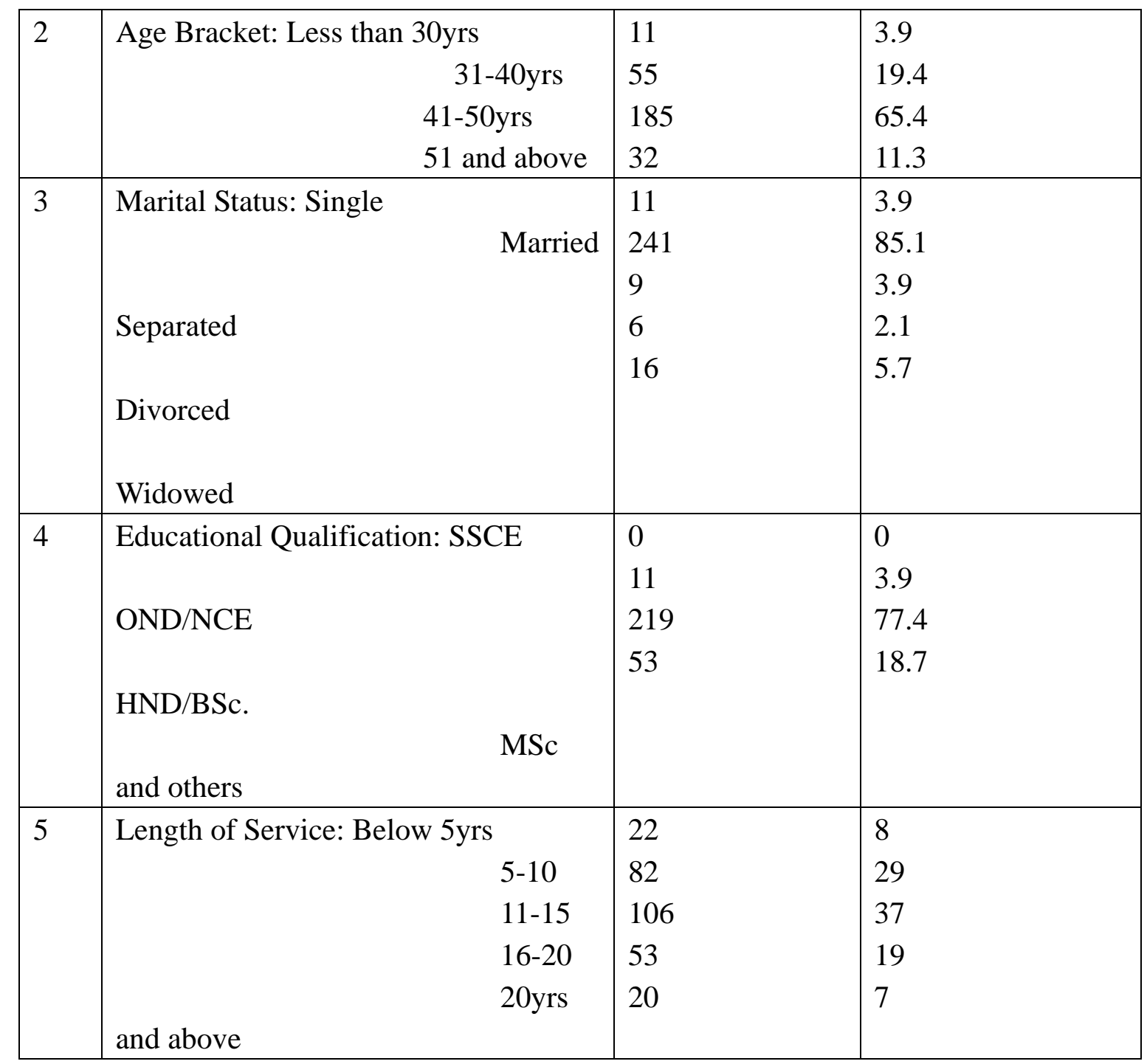

Source: Field survey, 2016.

Distribution based on gender characteristics: As shown in table 1 above regarding the gender distribution of the study, 184 which represents about $65 \%$ of the respondents were males while 99 which represents $35 \%$ of the respondents were females. This implies that though there were more of male respondents than females, both genders were duly represented.

Distribution based on Age of respondents: The data from table 1 has also shown the age distribution of the respondents from less than 30 years, to 51 years and above. The result reports that there were more respondents from the age bracket of 41-50 years of age. The result has shown that about $65.4 \%$ were of the age bracket of $41-50$ years while the next majority of respondents were from the age bracket of 31-40 years of age accounting about $19.4 \%$ of the respondents. There were about $11.3 \%$ of respondents from the age bracket of $\geq 51$ years while respondents with the age bracket of less than 30 years were the least participants in the study. This implies that there were more matured respondents for the study giving more credibility in the responses. 


\section{Al Macrothink}

Distribution based on marital status of respondents: The data in table 1 reports that a greater number of the respondents fall within the 'married' category(85.1\%), followed by those who were widowed(5.7\%), then those who were single(3.9\%), and separated(3.2\%) and divorced(2.1\%) .The result has indicated a high sense of maturity and responsibility on the part of the respondents for the study.

Distribution based on educational qualification of respondents: The data in table 1 above reports the level of respondents' education attainment. The result has shown that there were more respondents with HND/BSc. degree that participated in the survey as the result accounted about $77.4 \%$ of the respondents, followed by respondents with MSc./others accounting about $18.7 \%$ and very few of SSCE holders accounting about $3.9 \%$ of the respondents. This is a clear indication that majority of the respondents were academically qualified to understand and tackle the questions posed in the questionnaire.

Distribution based on years of service of the respondents: The data in table 1 above report the respondents' years of service. The result has shown that there were more respondents with about 8-10 years of experience as it accounted about 37\% of the respondents followed by respondents with 4-7years experience accounting about 29\%. Those with 11-14years of experience ranked third with $19 \%$. While respondents with below 3years and 15years and above were the least with $8 \%$ and $7 \%$ respectively. This implies that most of the chosen hotels were newly established but with great sense of innovation.

\subsection{Test of Hypotheses}

Hypothesis One

There is no significant association between the extent of innovation at any given period and the performance of the firms.

Table 2. Correlation analysis between the extent of innovation at any given period and the performance of the firms

\begin{tabular}{|c|c|c|c|c|}
\hline & & & EIF & $\mathrm{PF}$ \\
\hline \multirow{6}{*}{ Spearman's rho } & \multirow{3}{*}{ EIF } & $\begin{array}{l}\text { Correlation } \\
\text { Coefficient }\end{array}$ & 1.000 & $.150^{*}$ \\
\hline & & Sig. (2-tailed) & & .012 \\
\hline & & $\mathrm{N}$ & 283 & 283 \\
\hline & \multirow{3}{*}{ PF } & $\begin{array}{l}\text { Correlation } \\
\text { Coefficient }\end{array}$ & $.150^{*}$ & 1.000 \\
\hline & & Sig. (2-tailed) & .012 & \\
\hline & & $\mathrm{N}$ & 283 & 283 \\
\hline
\end{tabular}

In table 2, the Spearman rank correlation coefficient is 0.150 while the probability is 0.012 or 
1.2 percent which is less than 5 percent critical level. This implies that the correlation coefficient is significant. The researcher therefore concludes that there is a significant association between the extent of innovation at any given period and the performance of the firms.

\section{Hypothesis Two}

There is no significant correlation between innovation management and the growth of the firms

Table 3. Correlation analysis between innovation management and the growth of the firms

\begin{tabular}{|c|c|c|c|c|}
\hline & & & IMF & GF \\
\hline \multirow{6}{*}{ Spearman's rho } & \multirow{3}{*}{ IMF } & $\begin{array}{l}\text { Correlation } \\
\text { Coefficient }\end{array}$ & 1.000 & $.503^{* *}$ \\
\hline & & Sig. (2-tailed) & & .000 \\
\hline & & $\mathrm{N}$ & 283 & 283 \\
\hline & \multirow{3}{*}{ GF } & $\begin{array}{l}\text { Correlation } \\
\text { Coefficient }\end{array}$ & $.503^{* *}$ & 1.000 \\
\hline & & Sig. (2-tailed) & .000 & \\
\hline & & $\mathrm{N}$ & 283 & 283 \\
\hline \multicolumn{5}{|c|}{ **. Correlation is significant at the 0.01 level (2-tailed). } \\
\hline
\end{tabular}

The result in table 3 shows that innovation management is positively and significantly correlated to the growth of the firms. The correlation coefficient is 0.503 with a probability value of 0.000 indicating a significant relationship between the two variables. Thus, we reject the null hypothesis that innovation management does not significantly correlate to the growth of the firms while accepting the alternative hypothesis that innovation management does significantly correlate to the growth of the firms.

\subsection{Discussion of Findings}

Based on the analysis of the data above, it was discovered that:

1) There is significant association between the extent of innovation at any given period and the performance of the firms. This result implies that the extent of innovation determines the extent of performance within the firms. The more innovation is being beefed up, the more the firms' achievement in terms of performance. This finding is in line with the works of Calantone, Cavusgil and Zhao (2002) on firms' innovativeness and performance; Lin (2007); Terziovski (2010); Hajar (2015); and also with the work of Therrien, Doloreux and Chamberlain (2011) on impact of innovation on firm's performance in selected service industries. Their findings reveal that firm's innovativeness is positively related to their performance. This implies that the more the 
innovation being introduced, the more the productivity and overall performance of the firms.

2) Innovation management does significantly correlate to the growth of the firms. This result implies that innovation management correlates positively, though not having a complete influence on the growth of the firms. This finding is also in consonance with the work of Cho and Pucik (2005) titled "relationship between innovativeness, quality, growth and profitability and market value in US Finance industry”. The study in its methodology applied the Structural Equation Modeling method. The finding reveals that innovativeness mediates the relationship between quality and sustenance of the growth of the firm. The result has further reported that majority of the respondents affirmed to the opinion that innovation management significantly correlates to the growth of the firms.

\section{Summary of Findings}

1) There is a significant association between the extent of innovation at a given period and the performance of the firms. This buttresses the point that innovation is a veritable approach to increasing the performance of any firm and the more the practice, the more the result in terms of increase in performance. This is evidenced from the result of the correlation analysis indicating that there is significant association between the extent of innovation at a given period and the performance of the firms $(\mathrm{R}=0.150$ and $\mathrm{p}$-value $=$ $0.012)$.

2) Innovation management does significantly correlate to the growth of the firms. This implies that there is no growth in a growing world of business without a proper innovation management. Only firms with a strong penchant for success will be able to grow through a well-tailored innovation management. This is evidenced from the result of the correlation analysis which shows that innovation management does significantly correlate to the growth of the firms $(\mathrm{R}=0.503$ and $\mathrm{p}$-value $=0.000)$.

\subsection{Conclusion}

Innovation management has been a veritable tool towards bringing effectiveness to firms especially in the service industry. Based on the findings of the study, the following conclusions were made:

There is a significant association between the extent of innovation at any given period and the performance of the firms. The extent a firm has reached in terms of innovation goes a long way in determining their performance capacity. The more the practice, the more the result in terms of performance.

Innovation management does significantly correlate to the growth of the firms. That a firm is having a continuous growth today is simply as a result of continuous innovation, aside that the firm will stagnate and eventually go into oblivion. Only firms with a strong penchant for success and growth will be able to grow through a well-tailored innovation management. 


\subsection{Recommendations}

The essence of every research study of this nature is that at the end of the study, the researcher makes the necessary recommendations based on the concluded findings. Therefore, the following now form our recommendations:

1) There should be a concrete organizational arrangement to improve on the practice of innovation as often as possible in order to enhance the performance of the organizations.

2) The innovation management practice of the organizations should be extended to every unit or division so as to have a broad and even growth rather than a slim and lopsided growth as experienced by these hotels.

\section{References}

Agu, G. A. (2016). Data analysis for significant difference. In Anyanwu A. (ed.), Research methodology for business and social sciences, Owerri: Avan Global Press.

Alugbuo, C. C., Umeaka, E. C., \& Eriama, J. A. (2012). Research methodology with SPSS, Owerri: Credo Publishers.

Andreu, R., Baiget, J., \& Canals, A. (2003). Firm-specific knowledge and competitive advantage: Evidence and KM practices. Knowledge Process Management, 15(2), 97-106.

Artz, K.W., Normann, P.M., Hatfield, D.E., \& Cardinal, I.B. (2010). A longitudinal study of the impact of research and development, patents and product innovation on firm performance, Journal of Product Innovation Management, 27(5), 725-740. https://doi.org/10.1111/j-1540-5885-2010-00747.x

Calantone, R. J., Cavusgil, S. T., \& Zhao, Y. (2005). Learning orientation, firm innovation capability, and firm performance. Industrial Marketing Management, 31(6), 515-524.

Cho, H., \& Pucik, V. (2005). Relationship between innovativeness, quality, growth, profitability, and market value. Strategic Management Journal, 26(6), 555-570. https://doi.org/10.1002/smj.461

Duygulu, E., \& Ozeren, E. (2009). The effects of leadership styles and organization culture on firm's innovativeness. African Journal of Business Management, 3(9), 475-485. https://doi.org/10.5897/AJBM09.186

Easley, D. \& Kleinberg, J. (2010). Networks, crowds and markets: Reasoning about a highly connected world. London: Cambridge University Press.

Elci, S., \& Karatayh, I. (2009). Innovasyon El Kitabi, Technopolis Group Turkiye, Ankara.

Godin, B. (2008). Innovation: The history of a category. Project on the intellectual history of innovation. Montreal: INRS .62

Hajar, L. (2015). The effect of business strategy on innovation and firm performance in small 
industrial sector. The International Journal of Engineering and Sciences (IJES), 4(2), 1-09.

Hanekon, J. (2016). Seven ways to foster innovation in your company. [Online] Available: https://www.entrepreneur.com/...282664. Retrieved Sept.21

Hipp, C., Tether, B. S., \& Miles, I. (2000). The incidence and effects of innovation in services: Evidence from Germany. International Journal of Innovation Management, 4(4), 417-453. https://doi.org/10.1142/S1363919600000226

http//:www.innovation-management.org

http://blog.leanmonitor.com/early-adopters-allies-launching-product/

http://innovationzen.com/blog/2006/07/29/innovation-management-theory-part-1/

Karami, A. K. (2008). An inspection on environmental scanning and growth strategy in high tech sham firms. Conference on small firms -University of Twente, the Netherlands.

Kotler, P. (2003). Marketing management, New York: Prentice Hall International

LaMorte, W. W. (2016). Diffusion of Innovation Theory. Boston: Boston University School of Public Health. http://sphweb.bumc.bu.edu/otlt/MPH Modules/SB/BehavioralChangeTheories/BehavioralChangeTheories4.html

Lee, H., \& Yu, C. (2010). Effect of relation style on innovation performance. African Journal of Business Management, 4(9), 934-948. http://www.academicjournals.org/AJBM.

Lin, (2007). Does innovation lead to performance? An empirical study of small and medium enterprises in Taiwan. Management Research News, 30(2), 115-132.

Lipit, M. (2006). Patterns in innovation: Goals and organizational life-cycle, Human Resource Planning Society Journal, June, pp.73-77.

Oghojafor, B. E. A., Olamitunji, D., \& Sulaiman, A. A. (2011). Assessing the small and medium scale enterprises environment in Nigeria. International Journal of African Studies, 4, 22-27.

Okpara, G. S. (2013), Contemporary marketing: Topical and tropicalized (Revised Ed.), Enugu: John Jacobs Classic Publishers Ltd.

Rickne, A., Laestadius, S., \& Etzkowitz, H. (2012). Innovation governance in an open economy: Shaping regional nodes in a globalized world. United States and Canada: Routledge.

Rogers, E. M. (1962). Diffusion of innovations (1st ed.). Glencoe: Free Press.

Rogers, E. M. (2003). Diffusion of innovations, (5th Edition). New York: Free Press/Amazon. Rouse, M. (2016). Innovation management. searchcio.techtarget.com/definition/innovation-management. 


\section{Macrothink}

Schilling, M. A. (2013). Strategic management of technological innovation (4th ed.). New York, NY: McGraw-Hill/Irwin.

Schumpeter, J. (1934). The theory of economic development. Harvard, MA: Harvard Business Press.

Scocco, D. (2006). Innovation and Schumpeter's theories. [online] Available: innovationzen.com/blog/2006/07/29/innovation-management-theory-part-1/

Terziovski, J. (2010). Innovation and its performance implication in SMEs in manufacturing sector: A resource-based view. Strategic Management Journal, 31(8), 892-902.

Therrien, P., Doloreux, D., \& Chamberlin, T. (2011). Innovation novelty and (commercial) performance in the service sector: A Canadian firm-level analysis. Technovation, (31), 655-665. http://dx.doi.org/10.1016/j.technovation.2011.07.007.

\section{Appendix}

\section{Reliability Test Using SPSS version 19}

Scale: ALL VARIABLES

Case Processing Sum mary

\begin{tabular}{|rl|r|r|}
\hline & \multicolumn{1}{|c|}{$\mathrm{N}$} & \multicolumn{1}{c|}{$\%$} \\
\hline Cases & Valid & 32 & 100.0 \\
& Excludec & 0 & .0 \\
& Total & 32 & 100.0 \\
\hline
\end{tabular}

a. Listwise deletion based on all variables in the procedure.

Reliability Statistics

\begin{tabular}{|r|r|}
\hline $\begin{array}{c}\text { Cronbach's } \\
\text { Alpha }\end{array}$ & N of Items \\
\hline .863 & 24 \\
\hline
\end{tabular}




\begin{tabular}{|l|r|r|r|}
\hline \multicolumn{5}{|c|}{ Item Statistics } \\
\hline Question 1 & Mean & Std. Deviation & N \\
Question 2 & 1.34 & .483 & 32 \\
Question 3 & 2.28 & .683 & 32 \\
Question 4 & 1.63 & .707 & 32 \\
Question 5 & 3.16 & .515 & 32 \\
Question 6 & 2.19 & .859 & 32 \\
Question 7 & 4.19 & .644 & 32 \\
Question 8 & 4.28 & .581 & 32 \\
Question 9 & 2.59 & 1.160 & 32 \\
Question 10 & 4.25 & .622 & 32 \\
Question 11 & 4.03 & .933 & 32 \\
Question 12 & 4.25 & .622 & 32 \\
Question 13 & 4.31 & .535 & 32 \\
Question 14 & 4.56 & .504 & 32 \\
Question 15 & 4.75 & .508 & 32 \\
Question 16 & 4.47 & .671 & 32 \\
Question 17 & 4.25 & .622 & 32 \\
Question 18 & 4.56 & .669 & 32 \\
Question 19 & 4.06 & .914 & 32 \\
Question 20 & 4.31 & .535 & 32 \\
Question 21 & 3.84 & .762 & 32 \\
Question 22 & 4.56 & .723 & 32 \\
Question 23 & 4.47 & .564 & 32 \\
Question 24 & 4.28 & .567 & 32 \\
\end{tabular}

Scale Statistics

\begin{tabular}{|c|r|r|r|}
\hline Mean & Variance & Std. Deviation & N of Items \\
\hline 91.13 & 66.758 & 8.171 & 24 \\
\hline
\end{tabular}

\section{Copyright}

Copyright for this article is retained by the author(s), with first publication rights granted to the journal.

This is an open-access article distributed under the terms and conditions of the Creative Commons Attribution license (http://creativecommons.org/licenses/by/4.0/). 